\title{
차량용 $\mathrm{FMCW}$ 레이더의 탐지 성능 분석 및 신호처리부 개발
}

\author{
김상동* · 현유진* · 이종훈* · 최준혁** · 박정호** · 박상현***
}

The analysis of the detection probability of FMCW radar and implementation of signal processing part

Sang-Dong Kim* · Eugin Hyun* · Jong-Hun Lee* · Jun-Hyeok Choi** · Jung-Ho Park** · Sang-Hyun Park***

이 논문은 2010년도 $\mathrm{ADD}$ 의 FMCW 레이다/추적장치 신호처리 모듈 과제 연구비를 지원받았음

\section{요 약}

본 논문에서는 차량용 FMCW(Frequency Modulated Continuous Wave) 레이더의 도플러 주파수와 아날로그-디지 털 변환기 비트 수에 따른 탐지 성능 분석 및 신호처리부 개발을 진행하고자 한다. 성능 평가를 위한 $\mathrm{FMCW}$ 레이더 의 시스템 모델은 송신부와 수신부로 구성되어 있으며 채널은 가우시안 잡음 환경을 사용한다. 이론과 시뮬레이션 을 통해서 시스템 모델을 검증한다. 수신부에서는 수신 신호와 기준 신호사이의 부정합으로 인한 주파수 오차가 발생하게 된다. $75 \mathrm{~cm}$ 의 분해능를 갖는 $\mathrm{FMCW}$ 레이더에서 도플러 주파수가 약 $38 \mathrm{KHz}$ 이하인 경우 탐지 성능의 열 화가 발생하지 않음을 알 수 있다. 아날로그-디지털 변환기 비트에 따른 탐지 성능은 6비트가 최소의 비트로 결정될 수 있음을 알 수 있다. 그리고 FPGA를 이용하여 디지털 송신 파형 발생기를 위한 집적 디지털 신디사이저(Direct Digital Synthesis) 칩을 기반한 FMCW 레이더 신호처리부를 설계 및 구현을 진행한다.

\section{ABSTRACT}

This paper analyzes the detection probability of FMCW (Frequency Modulated Continuous Wave) radar based on Doppler frequency and analog-digital converter bit and designs and implements signal processing part of FMCW radar. For performance evaluation, the FMCW radar system consists of a transmitted part and a received part and uses AWGN channel. The system model is verified through analysis and simulation. Frequency offset occurs in the received part caused by the mismatching between the received signal and the reference signal. In case of Doppler frequency less than about $38 \mathrm{KHz}$, performance degradation of detection does not occur in FMCW radar with $75 \mathrm{~cm}$ resolution The analog-digital converter needs at least 6 bit in order not to degrade the detection probability. And, we design and implement digital signal processing part based on DDS chip of digital transmitted signal generator for FMCW radar.

\section{키워드}

$\mathrm{FMCW}$, 레이더, 도플러 주파수, 아날로그-디지털 변환기, 신호처리부

Key word

FMCW , radar, Doppler frequency, analog-digital converter, digital signal processing

* 대구경북과학기술원 (이종훈, jhlee@dgist.ac.kr)

** LIGNex1

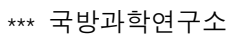

접수일자 : 2010. 10. 31 심사완료일자 : 2010. 11. 10 


\section{I. 서 론}

FMCW 레이더는 차량용 충돌방지 시스템에서 외부 환경에 영향을 받지 않고 차량의 거리를 측정할 수 있 는 기기로서 많은 관심을 받고 있다[1]-[8]. 충돌 방지 시스템은 자동차 근방에 장애물을 인지하여 시스템과 장애물간의 상대거리를 추출함으로서 미연에 충돌을 방지하는 것을 목적으로 가지고 있다. 장애물 감지센 서로는 초음파, 레이저 그리고 카메라와 같은 센서들 이 거론되고 있으나, 초음파는 단거리의 물체를 측정 하는 데만 사용되고, 레이저와 카메라는 눈과 비와 같 은 환경에서는 거리 인식의 어려움을 가지고 있다. 그 래서 이에 대한 대안으로 차량용 레이더는 환경에 상관 없이 눈, 비와 같은 운전자의 시야를 가리는 상황이나 운전자의 부주의로 인해 발생할 수 있는 사고를 미연에 방지하고 개발된 차량의 안전 운행 시스템으로 사용되 고 있다[3].

밀리미터파 레이더를 이용하는 충돌방지 시스템은 대부분 장거리 물체 탐지를 위한 $\mathrm{FMCW}$ 레이더를 사용 하고 있다. $\mathrm{FMCW}$ 레이더는 $\mathrm{W}$ band의 초고주파에서 광 대역 변조를 사용하기 때문에, 수 $\mathrm{cm}$ 까지 거리 해상도를 검출할 수 있는 장점이 있다. 그러나, $\mathrm{FMCW}$ 레이더가 고성능의 탐지 성능을 갖고 디지털로 동작하기 위해서 는 도플러 주파수에 따른 탐지 성능 분석과 아날로그-디 지털 변환기 비트수에 따른 탐지 성능 분석이 필요하다 [9]. 본 연구에서는 FMCW 레이더 신호처리 알고리즘 성 능 평가와 디지털 송신 파형 발생기를 위한 집적 디지털 신디사이저 칩을 기반한 신호처리부를 설계 및 구현하 였다.

본 논문의 구성은 2 장에서는 $\mathrm{FMCW}$ 레이더의 개요 에 대해서 나타내고, 3 장에서는 $\mathrm{FMCW}$ 레이더의 신호 처리 구성도를 나타낸다. 4 장에서는 시뮬레이션 결과 고찰과 구현을 기술하였고, 결론은 5 장에서 정리하였 다.

\section{ㅍ. FMCW 레이더 개요}

$\mathrm{FMCW}$ 레이더는 그림 1 과 같이 시간에 따라 선형 적으로 변하는 삼각파 신호를 송신하여 목표물로부터
반사되는 신호를 수신하게 된다. 송신 신호와 수신 신 호사이에는 거리에 따른 주파수 차이가 발생한다 [10]. 차주파수는 장애물로부터 반사된 수신신호와 송 신신호를 곱 $(\mathrm{Mix})$ 하는 방식을 사용하여 추출한다. 곱 해진 신호는 저대역주파수통과필터를 지나면 합주파 수는 제거되고 차주파수 성분만 남게 되어 이를 비트 주파수(fr, Beat frequency)라고 정의한다 [11]. 비트주 파수는 식 (1)에서 알 수 있듯이 거리 정보를 포함하고 있다.

$$
R=\frac{c T f r}{4 \pi B}
$$

여기서, B는 주파수 변조폭 또는 대역폭을 나타내며, $\mathrm{T}$ 는 FMCW 변조 주기 또는 신호 폭을 나타낸다.

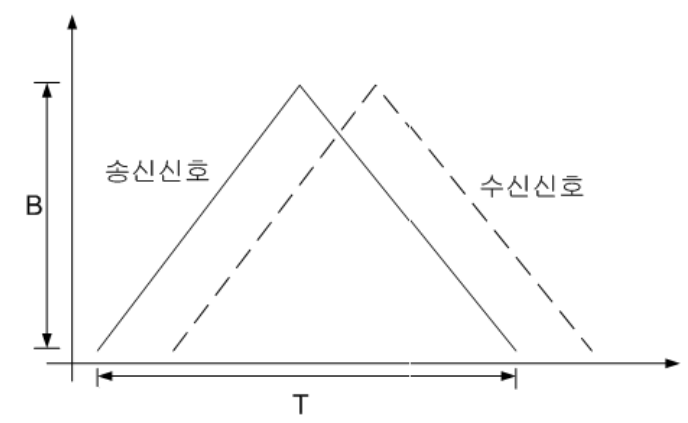

그림 1. FMCW 레이더 송수신 신호

Fig. 1 FMCW radar transmitted and received signal

그림 2는 $\mathrm{FMCW}$ 레이더의 시스템 블록도를 나타내 고 있다. 집적 디지털 신디사이저 칩을 이용하여 선형적 인 FMCW 레이더의 송신신호를 발생시키고, $\mathrm{W}$ band의 오실레이터를 곱한 후, 안테나를 통해서 목표물로 송신 을 하게 된다. 목표물의 거리에 따라 시간적으로 지연된 반사 신호가 수신 안테나를 통해서 수신되며 수신된 신 호는 송신신호와 곱해져서 비트 주파수 성분을 발생한 다. 비트 주파수 성분은 증폭기와 저대역 주파수 통과 필 터를 통과하여 증폭된 아날로그 신호가 아날로그-디지 털 변환기를 통해서 디지털 신호로 변환된다. 변환된 디 지털 신호는 고속 푸리에 변환기를 통해서 주파수성분 이 추출되고 추출된 주파수를 통해서 반사된 신호와 레 이더간의 상대거리를 알 수 있다. 
$\mathrm{FMCW}$ 레이더의 특성상 거리 분해능은 주파수 분해 능에 의해서 비례한다. 그러나, 움직이는 물체를 탐지하 는 경우에 $\mathrm{FMCW}$ 레이더의 수신신호에 도플러 주파수 가 더해지게 된다. 이는 주파수를 거리로 탐지하는 $\mathrm{FMCW}$ 레이더에서는 탐지성능의 열화를 발생하게 된 다. 레이더의 탐지성능은 최대탐지거리에서 약 $90 \%$ 이 상의 탐지율을 갖도록 요구하고 있으므로, 도플러 주파 수에 따른 탐지 성능 분석은 필연적으로 수행해야함을 알 수 있다. 그리고 $\mathrm{FMCW}$ 레이더는 RF 모듈을 통해서 수신된 신호를 디지털 신호로 변환해야 하므로 아날로 그-디지털 변환기의 비트수에 따라서 탐지 성능에 영향 을 미치는 것을 알 수 있다. 따라서, 본 논문은 도플러 주 파수와 아날로그-디지털 변환기 비트에 따른 성능 평가 를 분석하였다.

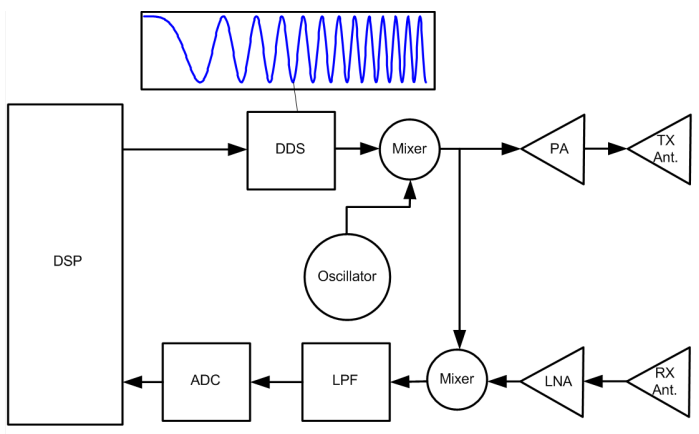

그림 2. FMCW 레이더 시스템 블록도

Fig. 2 FMCW radar system block diagram

\section{FMCW 레이더의 신호처리 구성도}

\section{1 신호처리 구성도}

본 절에서는 차량용 $\mathrm{FMCW}$ 레이더 신호처리부의 탐 지 성능을 분석하기 위한 시스템 모델을 분석한다. 그림 3 은 차량용 $\mathrm{FMCW}$ 레이더 시스템의 개략적인 디지털 송수신 구조를 나타내고 있다. $\mathrm{FMCW}$ 레이더 송신부에 서는 LFM(Linear Frequency Modulation) 전송 신호를 생 성하여, RF 모듈을 통해 목표물로 송신한다.

또한 목표물로부터 수신된 레이더 전송 펄스에 대 응하는 레이더 반사 펄스는 RF 모듈의 믹서와 곱해져 서 수신된 신호는 아날로그-디지털 변환기를 통해서 디지털 신호로 변환된다. 디지털 신호처부에서 고속
푸리에 변환기를 통해서 RF 모듈에서 수신된 신호의 주파수를 측정하고 최종적으로 차량용 $\mathrm{FMCW}$ 레이 더 시스템이 목표물과의 상대 거리를 인식할 수 있게 된다.

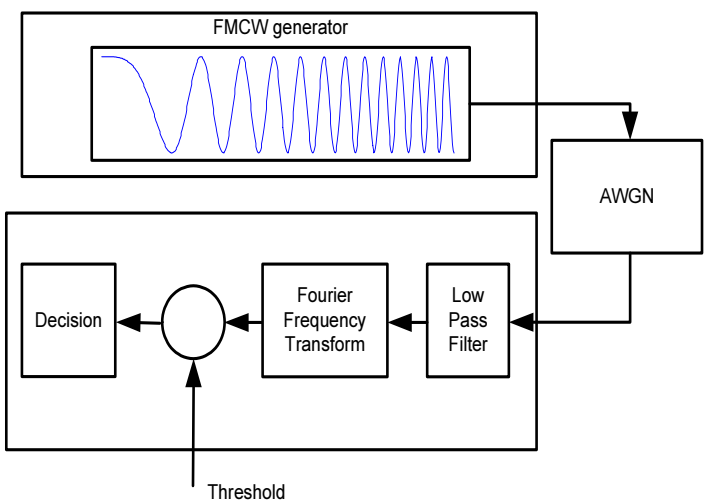

그림 3. FMCW 레이더 신호처리 구성도

Fig. 3 FMCW radar signal processing block diagram

3.2 FMCW 레이더 신호 모델

본 절에서는 $\mathrm{FMCW}$ 레이더에서 송신 신호와 상관된 수신 신호를 기술한다. FMCW 송신신호는 식 (2)와 같이 표현한다.

$$
w(t)=\cos \left(2 \pi\left(f_{0} t+\frac{B}{2 T} t^{2}\right)\right), 0 \leq t \leq T(2)
$$

여기서 $\mathrm{B}$ 는 $200 \mathrm{MHz}$ 대역폭이고 T는 $\mathrm{FMCW}$ 신호 폭 이며 33us이다.

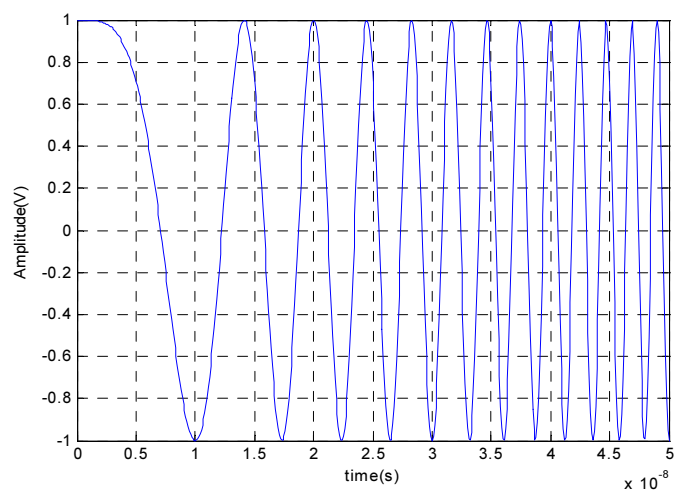

그림 4. 시간 영역에서의 $\mathrm{FMCW}$ 송신 신호 Fig. 4 FMCW transmitted signal in the time domain 
식 (3)는 식 (2)에서 나타내고 있는 FMCW 신호의 수 신신호는 다음과 정의한다.

$$
r(t)=\operatorname{acos}\left[2 \pi\left(f_{0}\left(t-\frac{2 R}{c}\right)+\frac{B}{2 T}\left(t-\frac{2 R}{c}\right)^{2}\right)\right]+n(t)
$$

여기서, $\mathrm{a}$ 는 수신 신호의 진폭이며, $\tau$ 는 반사체에서 의한 시간 지연을 나타내며, $\mathrm{R}$ 은 반사체의 거리이고, $\mathrm{c}$ 는 빛의 속도이며, $n(t)$ 는 가우시안 잡음을 나타내며, $\frac{n_{0}}{2}$ 의 파워 스펙트럼 밀도를 의미한다.

수신부에서는 식 (3)의 수신 신호가 믹서기를 통해서 송신 신호와 곱해진 후 저주파 대역 통과 필터를 지나게 되면, 수신 신호는 반사체의 시간 지연에 비례해서 일정 주파수를 갖는 정현파 신호로 변하게 된다[9]. 이 때, 정 현파 신호의 주파수는 다음과 같다.

$$
s(t)=\operatorname{acos}\left[\left(\frac{4 \pi B R}{c T}\right) t+f_{0} \frac{4 \pi R}{c T}\right]
$$

식 (4)에서 나타난 정현파 신호의 주파수를 고속 푸리 에 변환기 모듈을 통해서 탐지하게 되면, 레이더와 반사 체와의 거리를 계산할 수 있다.

\section{$\mathrm{IV}$. 시뮬레이션 결과 고찰과 구현}

4.1 FMCW 레이더의 아날로그-디지털 변환기 비트 에 따른 영향

본 절에서는 $\mathrm{FMCW}$ 레이더의 아날로그-디지털 변 환기 비트수에 따른 성능 분석을 하였다. 시스템 모델 은 참고문헌 [12]에서 제시된 모델을 사용하였다. 아날 로그-디지털 변환기의 양자화는 3비트에서 7비트까지 진행하였으며, 양자화된 아날로그-디지털 변환기값은 아날로그 값에서 디지털 값의 가장 가까운 값 중 높은 (Ceil) 값으로 설정하였으며, 오버플로우(Overflow) 값 은 포화시켰다(Saturate). 오류확률은 $10^{-2}$ 로 설정하여 시뮬레이션을 진행하였다. 그림 5 를 통해서, $\mathrm{FMCW}$ 레 이더의 탐지 성능에 영향을 미치지 않는 아날로그-디 지털 변환기 비트수는 최소 6비트라고 판단됨을 알 수 있다.

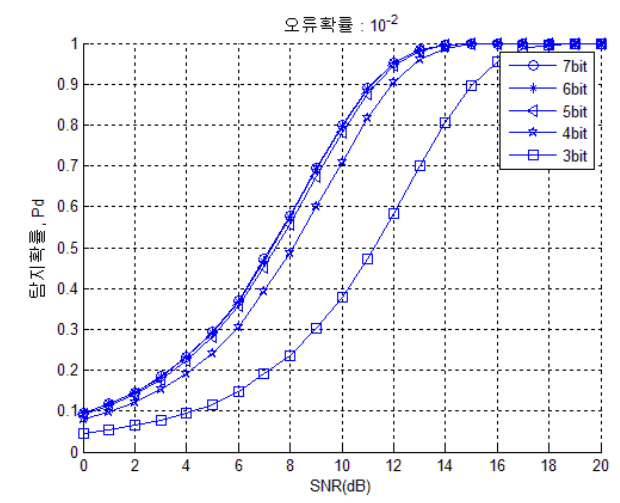

그림 5. 아날로그-디지털 변환기 비트 수에 따른 탐지 성능 결과

Fig. 5 The detection probability based on analog-digital converter bit

\subsection{FMCW 레이더의 도플러 주파수 영향}

본 절에서는 $\mathrm{FMCW}$ 레이더의 도플러 주파수가 탐지 성능에 미치는 영향에 대해서 기술한다. 도플러 주파수 가 고정된 값이라고 가정하였을 때, 수신기에서는 수신 신호와 기준 신호사이의 부정합으로 인한 주파수 오차 가 발생하게 된다. 이는 탐지 성능에 영향을 미치기 때문 에 시스템의 도플러 주파수 스펙을 결정해야 한다. $\mathrm{W}$ band의 시스템 파라미터는 T가 $33 \mathrm{us}, \mathrm{BW}$ 를 $200 \mathrm{MHz}$ 로 정하였다. $1 \mathrm{~m}$ 와 $1.75 \mathrm{~m}$ 의 반사체에서 반사되는 $\mathrm{FMCW}$ 레이더 수신 신호의 주파수는 각각 $250 \mathrm{KHz}, 444 \mathrm{KHz}$ 이 다. 이때, $1 \mathrm{~m}$ 에서 수신되는 신호에서 도플러 주파수에 따른 최대값으로 정규화시킨 고속 푸리에 변환기 결과 는 그림 6에서 나타내었다.

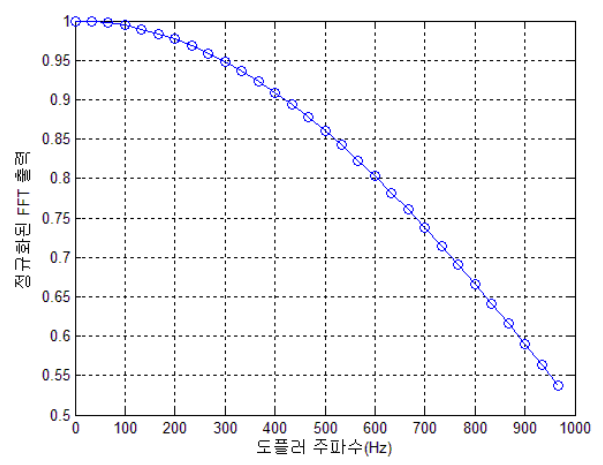

그림 6. 도플러 주파수에 따른 고속 푸리에 변환기 결과

Fig. 6 FFT result based on Doppler frequency 
그림 7은 도플러 주파수에 따른 탐지성능에 대해서 나타내고 있다. 오류 확률은 $10^{-2}$ 로 설정했다. 도플러 주 파수가 약 $38 \mathrm{KHz}$ 이내인 경우 탐지 성능이 거의 미치지 않는다.

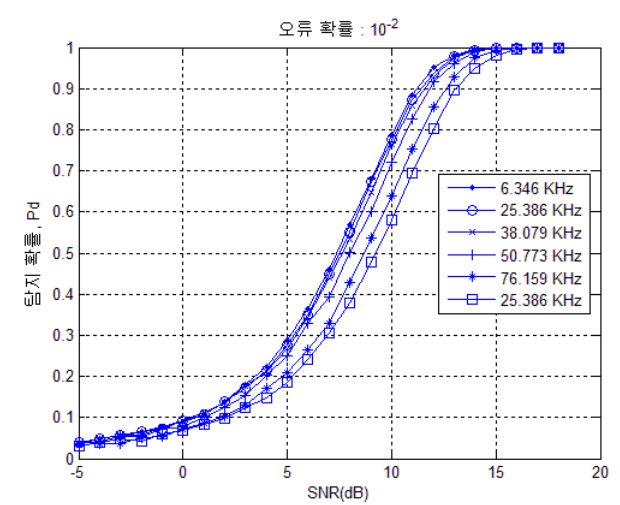

그림 7. 도플러 주파수에 따른 탐지 성능 영향 Fig. 7 The effect of detection performance based on Doppler frequency

4.2 FMCW 레이더 신호처리부 설계 및 구현 본 절에서는 $\mathrm{FMCW}$ 레이더의 거리 탐지 모듈의 신호 처리부를 설계 및 구현을 진행하고자 한다. $\mathrm{FMCW}$ 레이 더의 $\mathrm{RF}$ 모듈은 $\mathrm{W}$ 대역의 중심주파수와 $\mathrm{B}$ 는 $200 \mathrm{MHz}$ 의 스펙으로 구현하였다. 거리분해능은 $0.75 \mathrm{~m}$ 을 갖도록 설 계되었고, 이를 위한 $\mathrm{FMCW}$ 레이더 파라미터는 표 1 과 같다.

표 1. FMCW 레이더 파라미터

Table. 1 FMCW radar parameters

\begin{tabular}{|c|c|}
\hline 항목 & 값 \\
\hline \hline 주파수 대역폭(B) & $200 \mathrm{MHz}$ 이하 \\
\hline 샘플링 주파수(fs) & $5 \mathrm{Msps}$ \\
\hline 신호 폭(T) & $33 \mathrm{us}$ \\
\hline 고속 푸리에 변환기 길이 $(\mathrm{N})$ & $256 \mathrm{point}$ \\
\hline
\end{tabular}

신호처리부의 기능은 3 절의 그림 3 과 같이 진행하였 으며, 제시된 파라미터를 만족하고 다양한 기능을 시험 할 수 있도록 주요부분을 FPGA(field programmable gate array)로 구현하였다. 먼저, 아날로그 처리부를 살펴보
면, 수신신호는 FMCW 레이더의 비트주파수 신호이며 수 $\mathrm{MHz}$ 이내로 존재한다. 따라서, 수신부 아날로그-디 지털 변환기는 14 비트, $50 \mathrm{Msps}$ 인 Analog device사의 $\mathrm{AD} 9252$ 를 사용하여 구현하였다. $\mathrm{AD} 9252$ 의 스펙은 $50 \mathrm{Msps}$ 의 샘플링 속도에서 약 $93.5 \mathrm{~mW}$ 의 전력을 사용하 며, $\mathrm{SNR}$ 는 $73 \mathrm{~dB}$ 정도 갖으며, $2 \mathrm{Vp}-\mathrm{p}$ 의 신호를 수신받아 디지털 신호로 변환할 수 있다. 송신신호는 Analog device사의 $\mathrm{AD} 9910$ 의 집적 디지털 신디사이저 칩의 디 지털 램프 모듈레이션 모드를 이용하여 선형적인 $\mathrm{FMCW}$ 송신 파형을 만들었다.

집적 디지털 신디사이저 칩의 스펙은 $1 \mathrm{Gsps}$ 의 샘플 링을 할 수 있으며, 14 비트 디지털-아날로그 변환기를 포함하고 있다. 위상 잡음은 $-125 \mathrm{dBc} / \mathrm{Hz} @ 1 \mathrm{KHz}$ offset(400MHz carrier)를 갖는다. 디지털 변환된 신호 를 신호처리하기 위해서 사용된 FPGA는 Xilinx사의 XC5VLX330-FF1760를 사용하였으며, 추후 신호처리 의 확장성을 고려하여 고속 동작의 대용량 FPGA를 사 용하였다. 주요기능은 아날로그-디지털 변환기 신호 의 주파수를 추출하기 위한 고속 푸리에 변환기와 고 속 푸리에 변환기의 결과에서 거리를 추출하기 위한 임계치 탐지기를 수행한다.

디지털 신호처리의 핵심 기술인 고속 푸리에 변환기 를 설계하기 위해서 Xilinx사에서 제공하는 FFT LogiCore를 사용하였다. FFT LogiCore는 입력 비트를 8 에서 34까지 변 경할 수 있으며, Pipelined, streaming I/O 방식, Radix-4 Burst I/O방식 그리고 Radix-4 Burst I/O방 식 등을 사용할 수 있으며, 본 논문에서는 FPGA 내부 블록램과 slice를 작게 사용하면서도 처리 속도가 빠른 Pipelined, streaming $\mathrm{I} / \mathrm{O}$ 방식을 사용하였다. 본 논문을 위해서 설계된 16비트와 256-point 고속 푸리에 변환기 의 하드웨어 성능은 DSP slice를 24개 사용하였으며, $18 \mathrm{~K}$ 블록램을 2 개 사용한다. 처리 속도는 256 -포인트 고속 푸리에 변환기를 수행하는 데 861 사이클을 필요 로 하였으며, $50 \mathrm{MHz}$ 의 클럭속도로 환산하면, 약 $17.22 \mathrm{us}$ 의 처리 시간이 걸린다.

그림 8은 FPGA에서 개발된 256-포인트 고속 푸리에 변환기를 검증하기 위해서 고속 푸리에 변환기의 실수 부에 사인파를 입력으로 하고, 허수부에 0 을 입력으로 하였다. FPGA내의 256-포인트 고속 푸리에 변환기의 결 과는 매틀랩으로 수행한 결과의 오차값이 최대 $1 / 2^{\wedge} 16$ 만큼 나왔다. FFT는 범용적으로 많이 사용하기 때문에, 
기존의 연구에 따른 FFT의 결과는 매틀랩에 정의되어 있으며, 이와 비교하였을 때 개발된 FFT는 문제없이 사 용될 수 있음을 알 수 있다. 그림 9은 FPGA에서 개발된 256-point 고속 푸리에 변환기의 결과를 Xilinx사의 ISE 프로그램에서 결과 파형을 나타내고 있다. 이 결과는 그 림 8의 (b)의 결과에서 나타내었다.

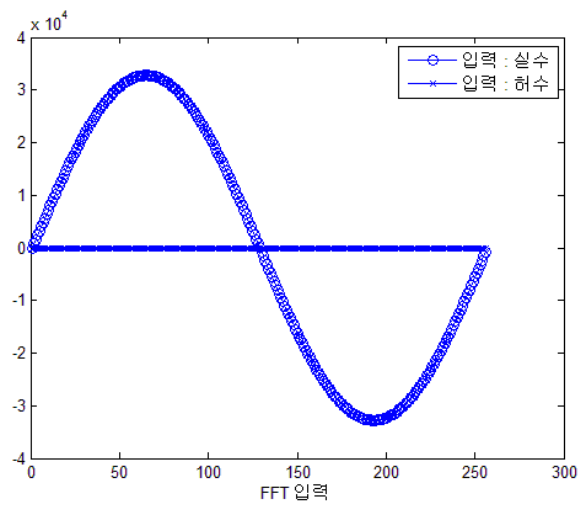

(a)

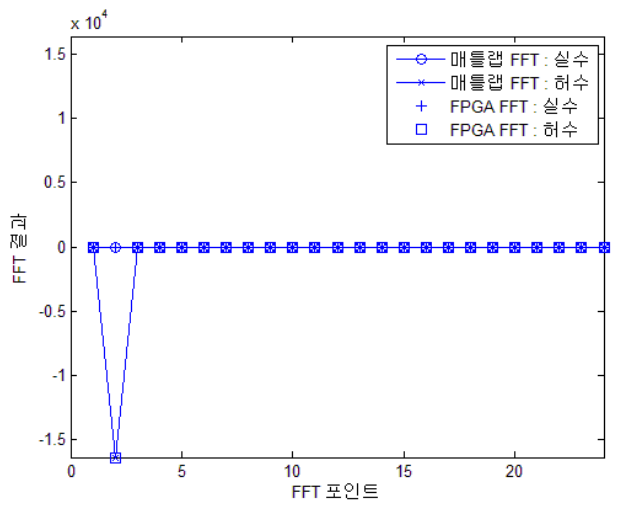

(b)

그림 8. (a) 256-포인트 고속 푸리에 변환기 입력 값 (b) FPGA 고속 푸리에 변환기결과와 매틀랩 고속 푸리에 변환기 결과 비교 결과

Fig. 8. (a) 256-point FFT input (b) FPGA FFT results and matlab FFT results

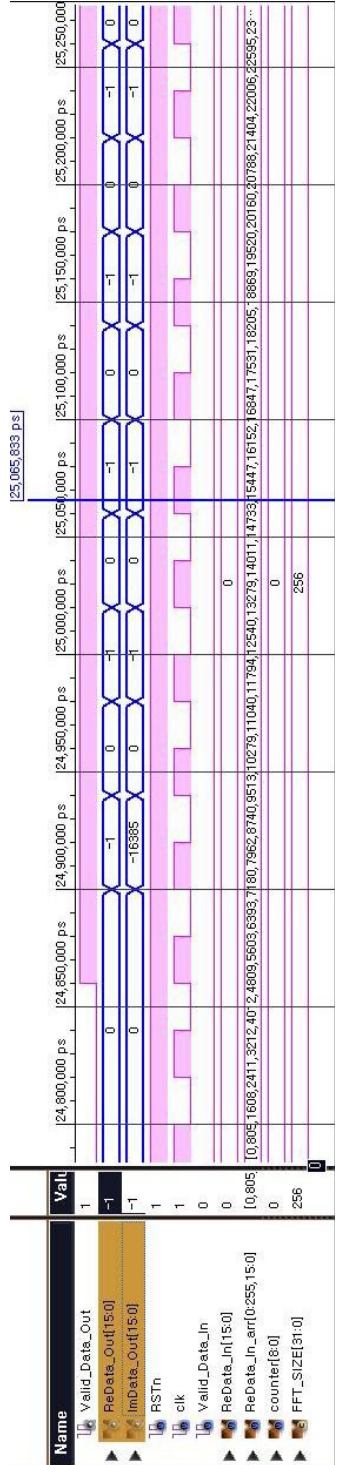

그림 9. $\mathrm{FPGA}$ 의 고속 푸리에 변환기 결과 Fig. 9. the FFT results of FPGA

\section{$\mathrm{V}$. 결 론}

본 논문에서는 차량용 $\mathrm{FMCW}$ 레이더의 도플러 주 파수와 아날로그-디지털 변환기 비트 수에 따른 탐지 성능 분석 및 신호처리부 설계 및 구현을 진행하였다. 탐지 성능 평가를 위한 $\mathrm{FMCW}$ 레이더의 시스템 모델 
은 송신부와 수신부로 구성하였으며 채널은 가우시안 잡음 환경을 사용하였고, 분석과 시뮬레이션을 통해 서 시스템 모델을 검증하였다. 수신부에서 도플러 주 파수에 의해서, 기준 신호와 수신 신호사이의 부정합 으로 인한 주파수 오차에 의해서 $\mathrm{FMCW}$ 신호는 도플 러 주파수가 약 $38 \mathrm{KHz}$ 이내인 경우 탐지 성능의 열화 가 발생하지 않음을 알 수 있었다. 아날로그-디지털 변 환기 비트에 따른 탐지 성능은 6비트가 최소의 비트로 결정할 수 있음을 알 수 있었다. 마지막으로 FPGA를 이용하여 디지털 송신 파형 발생기를 위한 집적 디지 털 신디사이저 칩을 기반한 $\mathrm{FMCW}$ 레이더 신호처리 부를 설계 및 구현을 진행하였다. 향후 본 논문에서 제 시된 도플러 주파수와 아날로그-디지털 변환기의 결 과를 적용하여 차량용 $\mathrm{FMCW}$ 레이더가 개발될 것으 로 기대된다.

\section{감사의 글}

본 연구는 2010년도 국방과학연구소의 지원에 의 하여 이루어진 연구로서, 관계부처에 감사 드립니다.

\section{참고문헌}

[1] P. E. Ross, "Top Ten Tech Cars-2010", IEEE spectrum, Apr.,2010,pp. 28-58.

[2] 홍주연, 강동민, 윤형섭, 심재엽, 이경호, “전방감시 용 밀리미터파 레이더 기술 동향”, 전자통신동향분 석 제 22권 제 5호 2007년 10월.

[3] 오우진, "FMCW 방식의 자동차 레이더 신호처리부 설계 및 구현”, 전자공학회논문지 제 41권 제 $\mathrm{TC}$ 편 제 12호, 2004년, 12월, pp. 67 74.

[4] 현유진, 오우진, 이종훈, "77GHz 차량용 레이더 신 호처리부 구현”, 대한전자공학회 하계종합학술대 회, 2009년, 7월, pp. 1119 1120.

[5] W. Chang, L. Huan, L. Yubai, "A Practical FMCW Radar Signal Processing Method and Its System Implementation", in Int. Conf. ITS Telecomm., 2006, pp.1195 1199.
[6] H. Rohling and R. Mende, "Waveform Design Principles for Automotive Radar Systems", in CIE Int. Conf., 2001, pp.1 4.

[ 7 ] H. Rohling and R. Mende, "OS CFAR performance in a $77 \mathrm{GHz}$ radar sensor for car application", CIE International Conference of Radar, Oct. 1996, pp. 109-114.

[ 8 ] K. Cheng and H. Su,"Multi-target Signal Processing in FMCW Radar System with Antenna Array", Radar Conf., 2008 Radar'08, IEEE, pp.1 5.

[9] B. R. Mahafza, "Radar Systems Analysis and Design using Matlab," Chapman \& Hall/CRC, 2000

[10] 김민준, 천이환, 김주헌, "real FFT를 이용한 FMCW 레이더 신호처리," 한국해양정보통신학회논문지, 제 11권 제 12호, 2007년, pp.2227 2232.

[11] 오우진, 이종훈, “차량용 $\mathrm{FMCW}$ 레이더 신호처리 부 개발 및 주행시험," 한국해양정보통신학회논문 지, 제 14권 제 7호, 2010년, pp.1565 1571.

[12] S. D. Kim and J. H. Lee, "Performance analysis of LFM-UWB radar based on Doppler frequency", International Conference on ICT Convergence(ICTC), Nov., 2010, pp.297 298.

[13] S. M. Kay, "Fundamentals of statistical signal processing, Volume 2: detection theory, "Prentice Hall, 1993, pp. 67-70.

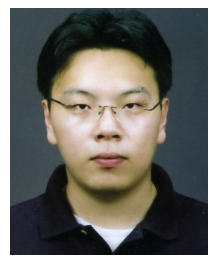

\section{김상동(Sang-Dong Kim)}

2004년 한양대학교

전자컴퓨터공학부 공학사

2006년 한양대학교 전자통신전파 공학화 공학 석사

현재, 대구경북과학기술원 연구원 ※관심분야: UWB, 차량용 레이더, 통신용 신호처리 


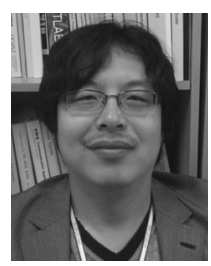

\section{현유진(Eugin Hyun)}

1999년 영남대학교 전자공학과 공학사

2001년 영남대학교 전자공학과 공학 석사

2005년 영남대학교 전자공학과 공학 박사 현재, 대구경북과학기술원 선임연구원. 2007년 현재 영남대학교 전자공학과 겸임교수 ※관심분야: 레이더 신호처리, 디지털 신호 프로세서 설계

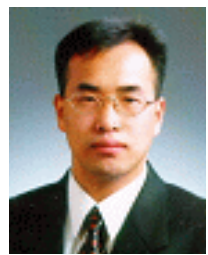

\section{이종훈(Jong-Hun Lee)}

1996년 성균관대학교 전자공학과 공학사

1998년 성균관대학교 전기전자 컴퓨터공학과 공학 석사

2002년 성균관대학교 전기전자컴퓨터공학과 공학박사 2002년 2005년 삼성전자 통신연구소 책임연구원 2005년 현재, 대구경북과학기술원 과제책임자/ 선임연구원.

2007년 현재, 영남대학교 정보전자공학부 겸임교수 ※관심분야: 레이더/비전 융합신호처리, 차량용 레이더

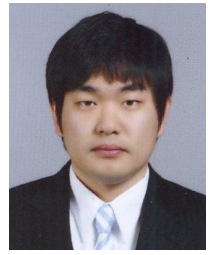

\section{최준혁(Jun-Hyeok Choi)}

2007년 경북대학교 전자전기 컴퓨터학부 공학사 2009년 경북대학교 전자전기 컴퓨터학부 공학석사

현재, LIG넥스원 ISR 연구센터 주임연구원 ※관심분야: 레이더 신호처리, 디지털 신호처리

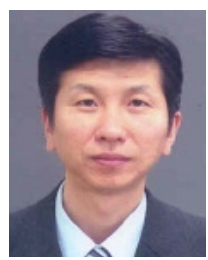

박정호(Jung-ho Park)

1988년 연세대학교 전자전산기공학사

1990년 연세대학교 전자전기공학과 석사

2001년 포항공대 전자전기 공학과 박사 현재, LIG넥스원 ISR 연구센터 수석연구원 ※관심분야: 레이더 신호처리, 레이더 체계공학

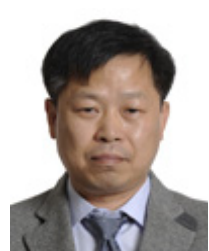

\section{박상현(Sang-Hyun Park)}

1990년 한국과학기술대학 전자공학과 학사

2001년 충남대학교 전파공학과 석사

1990년 현재 국방과학연구소 연구원

※ 관심분야: 레이더, RF 회로설계, 디지털 신호처리 